\title{
Review of human-animal interactions and their impact on animal productivity and welfare
}

Idrus Zulkifli

\begin{abstract}
Humans and animals are in regular and at times close contact in modern intensive farming systems. The quality of human-animal interactions can have a profound impact on the productivity and welfare of farm animals. Interactions by humans may be neutral, positive or negative in nature. Regular pleasant contact with humans may result in desirable alterations in the physiology, behaviour, health and productivity of farm animals. On the contrary, animals that were subjected to aversive human contact were highly fearful of humans and their growth and reproductive performance could be compromised. Farm animals are particularly sensitive to human stimulation that occurs early in life, while many systems of the animals are still developing. This may have long-lasting impact and could possibly modify their genetic potential. The question as to how human contact can have a positive impact on responses to stressors, and productivity is not well understood. Recent work in our laboratory suggested that pleasant human contact may alter ability to tolerate various stressors through enhanced heat shock protein (hsp) 70 expression. The induction of hsp is often associated with increased tolerance to environmental stressors and disease resistance in animals. The attitude and consequent behaviour of stockpeople affect the animals' fear of human which eventually influence animals' productivity and welfare. Other than attitude and behaviour, technical skills, knowledge, job motivation, commitment and job satisfaction are prerequisites for high job performance.
\end{abstract}

Keywords: Animal welfare, Fear, Human-animal interactions, Productivity, Stress

\section{Introduction}

Farm animals have undergone the process of domestication, a continuing genetic process aimed at modifying the animal's behaviour, anatomy and physiology to suit mankind's specific needs [1]. Hence, domestic animals should be adapted to man and captive environment. However, many farm animals still perceive contact with humans as an alarming predatory encounter and sudden changes in their physical and social environment as a frightening experience [2,3]. In modern production systems, there are regular periods of contacts between humans and animals such as during feeding and cleaning. Animals may respond to tactile, visual, olfactory, gustatory and auditory stimuli from humans. Even with considerable automation in intensive farming, animals are still subjected to some degree of human contact. The behaviour of stockpersons is an important factor in determining the degree of animals' fear in humans and consequently the

Correspondence: zulkifli@agri.upm.edu.my

Institute of Tropical Agriculture, and Department of Animal Science,

Universiti Putra Malaysia, 43400, UPM, Serdang, Selangor, Malaysia quality of the human-animal interaction [4]. Fear for humans is a major source of stress and may result is poor productivity in farm animals. This subject has been extensively reviewed previously [4-7].

The quality of human-animal interaction can have a profound impact on many facets of an animal's physiology and behaviour. Interactions by humans may be neutral, positive or negative in nature. Regular positive contact with humans is desirable in both mammalian and avian species [8]. On the other hand, farm animals that were handled aversively were highly fearful of humans, distressed and consequently their welfare and productivity will be compromised [5]. There have been considerable reports of attempts to alter the physiology, behaviour and performance pigs, poultry and cattle through regular positive contact with humans at both laboratory and farm levels $[6,9]$. The aim of this paper is to review some of the research that shows impact of human-animal interactions on the productivity and welfare of farm animals.

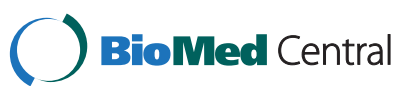




\section{The concept of human-animal interactions}

According to Estep and Hetts [10], human-animal interactions can be defined as the degree of relatedness or distance between animal and humans. A relationship develops between the stockperson and an animal in his / her care. The relationship requires mutual individual recognition. Animals may respond to tactile, visual, olfactory, gustatory and auditory stimuli from humans. The quality of human-animal interactions will determine whether the influence on an animal's physiology and behaviour is desirable or otherwise [5]. There is the question of whether animals can discriminate one human to another human. Literature regarding the ability of farm animals to recognise individual people is inconsistent. A number of experiments suggested that farm animals respond the same way to different people. Hemsworth [11] compared the response of pigs to two different stockpersons which differed markedly in their nature of contact with pigs. The authors concluded that pigs were unable to differentiate between different people and aversive handling by one person made the animals fearful of all people. Jones [12] indicated that chicks that had been habituated to one person by a regimen of regular handling also showed less fear of similarly dressed but otherwise dissimilar people. On the contrary, other studies showed that pigs [13,14], laying hens [15] and sheep [16] were able to recognise individual people. Rybarczyk [17] suggested that dairy cows may recognise people by their faces [17].

\section{Modifying the stress and fear reactions in animals through human-animal interactions}

Stress can be defined as any disruption of an animal's homeostatic equilibrium requiring the animal to make some responses to maintain its psycho-physiological integrity [18]. The life of a farm animal is constantly challenged by an array of factors that may evoke stress responses. Overcrowding, extreme temperatures, social disruption, unfamiliar sounds, unfamiliar or uncaring handlers, feed and water restriction, injection with antigens, disease are common environmental factors that may disrupt homeostasis. Biological reactions to stress comprise changes in behaviour, neuroendocrine system, autonomic nervous system and immune system [19]. In many stressful events, the first line of defence is behavioural response, which is biologically economic. When the biological system fails to cope with the stressor(s) and behavioural activity is suppressed, an animal depends on the integrative capacities of nervous and endocrine systems. Regardless of whether the stimulus is threatening or not, two distinct pathways involving interlocking physiological reactions will be evoked. The first pathway comprises the sympathetic adreno-medullary (SA) system that is responsible for the increase in the synthesis and release of cathecolamines (adrenaline and noradrenaline). The SA system reaction is manifested by immediate increases in blood pressure, muscle tone, nerve sensibility, respiration rate and blood sugar. Although the system may have dramatic physiological consequences, it is short term. Activation of the hypothalamic-pituitaryadrenal axis is a longer adjustment to environmental fluctuations. Sensory inputs cause the release of corticotrophin-releasing hormone form the hypothalamus. The neurohormone stimulates the anterior pituitary gland to release adrenocorticotrophin hormone that elicits the adrenal cortex to release glucocorticoids (cortisol and corticosterone). Glucocorticoids are known to modulate immune response, shift metabolism, influence growth, and alter behaviour [20]. Changes in the circulating levels of cortisol or corticosterone are routinely used to measure an animal's response to stress.

Stress and fear are not synonymous but the latter may contribute to overall stress, particularly if the frightening stimulation is intense, prolonged or inescapable [21,22]. According to Jones [8], fear is an emotional (psychophysiological) response to perceived danger. Gray [23] defined fear as a form of emotional reaction to a stimulus that the animal works to terminate, escape from, or avoid. High levels of fear not only represent a state of suffering but they are also a powerful and potentially damaging stressor. Two of the commonest and potentially frightening events encountered by farm animals are sudden changes in their social or physical environment and their exposure to people [8]. Animals probably perceive a new unfamiliar environment with a degree of uncertainty that acts as a psychological stimulus. In pigs, short-term exposure to a novel environment induced both behavioural and emotional reactions such as increased locomotive activity and escape attempts, vocalization, and as well as hormonal responses [24]. Novel environment is a potent fear- and stress-elicitor in all animals. Zulkifli et al. [25], and Zulkifli and Siti Nor Azah [26] noted elevation of heterophil / lymphocyte ratios (HLR) 24 h following transfer of chicks to new home cages. Translocation of chicks from the hatcher to brooding cages or pens may result in behavioural inhibition and panic [8].

The predominant response of the domestic fowl to humans is thought to be one of fear [27]. Naive chickens may perceive contact with humans as an alarming predatory encounter. It is common for farm animals to display fear-related behaviour in the presence of humans such as withdrawal from or avoidance of humans, immobility such as freezing or crouching [9,21]. Fear of humans in farm animals can be measured by home cage avoidance test, box plus experimenter and approaching human test [8]. The approaching human test is useful for commercial poultry flocks raised in floor pens. An experimenter can film the withdrawal responses of 
chickens as he walks slowly through a chicken house. Orientation away and withdrawal from the approaching human may be equated with fear levels. It is well documented that procedures with high human involvements, such as catching, loading and unloading can evoke both stress and fear reactions which may compromise chickens' welfare [28-30]. Hemsworth and Gonyou [5] indicated that pigs exhibited marked avoidance of humans following imposition of daily negative interactions as little as 15 to $30 \mathrm{~s}$.

There is considerable report to suggest that regular positive human contact is a powerful and reliable method to dampen stress and fear reactions in pigs [31], dairy cows [32], goats [33], and poultry [26,34,35]. AlAqil et al. [35] subjected broiler chicks to a pleasant physical contact daily for $30 \mathrm{~s}$ from 1 to $28 \mathrm{~d}$ of age. The authors found that those chickens had lower HLR, plasma levels of corticosterone (CORT), and shorter tonic immobility (TI) duration than their neglected counterparts following road transportation. Jones [8] suggested that the benefit of regular handling was specifically reducing birds' fear of humans rather than through any effect on their underlying fearfulness. However, during transit chickens may be exposed to an array of stressful and fearful stimuli including thermal extremes, acceleration, vibration, motion, impacts, feed and water deprivation, social disruption and noise [36]. Similarly, Lyons [37] reported that early human contact not only influenced behavioural responses to humans but also to novel stimuli. Hence, the findings of Lyons [37], and AlAqil et al. [35] showed that regular pleasant human contact may attenuate nonspecific underlying fearfulness in animals.

There is evidence that poultry are also sensitive to visual contact with humans [26,38,39]. Zulkifli et al. [34] reported that visual contact procedure involving the experimenter standing in the centre of a pen (with no attempted physical contact with birds) for 10 min twice daily from 0 to $3 \mathrm{wk}$ reduced fear and stress reactions to handling and crating. Jones [38] demonstrated that visual contacts without tactile interaction was more effective in reducing fear of humans than picking up and stroking the birds. Visual contact is obviously more feasible and practical than physical contact in commercial poultry flocks. There is, however, limited documented work on visual contact with humans, on stress and fear responses in non-avian species.

One of the earliest studies on the effect of early age stimuli on physiological stress response was by Levine [40] who reported that infantile stimulation through handling elicited long lasting alterations of the adrenocortical function in rodents. When adults, these rats had lower CORT both basally and during recovery, after withdrawal of stressors than those that were not handled, Gross [41] suggested that stimulation which occur early in life while many systems of the animals are still developing may have long lasting impact and could possibly modify expression of their genetic potential. Studies in pigs demonstrated that early handling during the first eight wk of life increased the approach behaviour of pigs to an experimenter in a standard test from 10 to 24 wk of age [42]. Zulkifli et al. [34] compared the effect of regular visual contact from 0 to $3 \mathrm{wk}, 0$ to $6 \mathrm{wk}$ and 3 to $6 \mathrm{wk}$ in chickens subjected to crating at $42 \mathrm{~d}$ of age. Chickens subjected to visual contact from 3 to $6 \mathrm{wk}$ showed longer TI durations and higher HLR in response to crating than those interacted at other ages. Based on these studies, it appears that early age human contact may have long-term effects. On the other hand, Jones and Waddington [43] reported that fear of humans in 20-day-old chicks was equally reduced irrespective they were handled from 0 to 9,10 to 18 , or 0 to $18 \mathrm{~d}$ of age.

It is not clear whether the quality of human contact experienced by animals at an early age can be modified by subsequent pleasant or unpleasant interaction with humans. This is critical under commercial setting because there will be variation both between and within stockpersons in their behaviour toward farm animals. Al-Aqil et al. [35] subjected chicks to either a combination of pleasant-unpleasant or unpleasant-pleasant physical contacts from 1 to $14 \mathrm{~d}$ and 15 to $28 \mathrm{~d}$ of age, respectively. Based on HLR and CORT reactions to road transportation, the authors concluded that the benefits of early age positive human contact can be modified by subsequent unpleasant experience with humans. The authors also indicated that chickens which had experienced pleasant human contact early in life may perceive the presence of humans as a signal for continuous positive interaction. Hence, subsequent exposure to unpleasant human contact may result in disappointment with consequent elicitation of the physiological stress response.

\section{Effect of human-animal interactions on animal productivity}

There is substantial evidence of a negative relationship between underlying fearfulness and productivity in farm animals $[4,5]$. Because positive interaction can reduce fear of humans, such practice may enhance productivity of farm animals. Gross and Siegel [44] postulated that positive human contact may reduce the resources otherwise required by animals to respond to their human associates and that resources can be utilised for productivity. In poultry, some authors [44-46] reported a significant improvement in weight gain and feed efficiency in positively handled chickens. The enhanced disease resistance and immune response in those studies could be associated with the stress modulating effect of human contact. However, others demonstrated that positive tactile interaction 
either had negligible [47] or negative effect [48] on growth performance. Nature of the physical contact, breed and age differences may have accounted for the discrepancies. Zulkifli et al. [34] reported that regular visual contact, irrespective of age, had no effect on weight gain, feed intake, FCR and mortality rates of broiler chickens. Zulkifli and Siti Nor Azah [26] compared the effects of physical and visual contacts and showed only the former was beneficial in enhancing growth performance. Physical contact which involved picking up and stroking the chickens appeared to be more "interactive" than visual contact in broiler chickens. In laying hens, however, Barnett et al. [39] showed that regular visual contact which reduced the subsequent avoidance behaviour of laying hens improved egg production.

According to Hemsworth and Coleman [26], fear of humans may be considered as one of the major factors for depressed growth and reproductive performance in commercial pigs. Hemsworth et al. [31] subjected gilts to either pleasant or unpleasant human contact three times per week for $2 \mathrm{~min}$ in duration from 11 to $22 \mathrm{wk}$ of age. The authors noted gilts in the pleasant handling treatment had significantly better weight gain but not feed efficiency than those in the unpleasant handling treatment. Unpleasant physical contact with humans reduced testicle size and delayed co-ordinated mating response in boars when compared to those subjected to positive handling by humans. In the similar study, gilts in the unpleasant treatment showed a lower pregnancy rate than those in the pleasant treatment. Work by Paterson and Pearce [49], and Pearce et al. [50], however, suggested that the growth response of pigs housed in groups was not affected by regular aversive handling by humans. There is a possibility that pigs raised in large groups may receive psychological protection from members of the group.

There have been relatively few human contact and productivity studies in other farm animals. Rushen et al. [51] showed that pleasant human contact had negligible effect on milk yield but reduced some behavioural signs of agitation in dairy cattle that were stressed due to milking in an unfamiliar environment. The authors concluded that human contact is not sufficient to reduce neuroendocrine reaction to novelty / isolation stress.

\section{Effect of human-animal interactions on animal health}

The immune system, once considered an autonomous system, is integrated with other physiological systems and is sensitive to regulation of the brain [52]. Because human contact may result alterations in brain physiology and morphology [53] it is possible that immune response and disease resistance will be affected. It is well established that farm animals encountering challenging conditions often show some degree of immunosupression [54-57].
Chronic activation of the hypothalamic-pituitary-adrenal axis and the sympathetic-adrenal-medullary axis results chronic production of corticosteroids and cathecolamines, respectively. Lymphocytes, monocytes or macrophages and granulocytes, exhibit receptors for corticosteroids and cathecolamines, which can alter cellular trafficking, proliferation, cytokine secretion, antibody production and cytolytic activity [58].

Because fear is a potent stressor, reducing fear of humans in farm animals through positive human contact may enhance the health of animals. Other than poultry there is a lack of information on the effect of human contact on the immune response and disease resistance in farm animals. Gross and Siegel $[44,59,60]$ reported that chickens habituated to humans through pleasant contact were more resistant to Escherichia coli and Staphylococcus aureus infections and had greater antibody production against erythrocyte antigens than those that were ignored. Zulkifli et al. [34] indicated that regular visual contact from 0 to 3 , and 0 to $6 \mathrm{wk}$ of age may improve antibody production against Newcastle disease vaccine. Similarly, Barnett et al. [39] showed that hens subjected to regular pleasant human contact had improved cell-mediated immune response to a mitogen when compared to the chickens that received negative human contact. The benefit of human contact improving disease resistance and immune response could be associated with its effect on modulating physiological stress response.

\section{How do positive human-animal interactions improve animal productivity and welfare?}

There is the question of how positive human-animal interaction can improve productivity and modify physiological stress response of farm animals. At any particular time, resources available to an individual are finite. Hence, competition for resources between body functions such as growth, reproduction and health will always occur [57]. The resources required to respond to prolonged and severe stress may be significant. Gross and Siegel [9] suggested that habituation to humans reduces the resources otherwise needed by the bird to respond to subsequent human contact, and these resources could be used either for coping 'with other environmental stressors of for productivity.

Jones [8] suggested that regular human contact exerts its effect by specifically reducing chickens' fear of humans. For example regular handling failed to influence chicks' reactions to unfamiliar places and objects $[61,62]$. On the contrary, Lyons [37] reported that early human contact not only influenced behavioural reaction of goats to human exposure but also a range of novel stimuli. Al-Aqil et al. [35] showed that regular pleasant human contact reduced stress and fear reactions to road 
transportation in broiler chickens. Although road transportation involved handling by humans, it is a multifactorial process which include feed and water deprivation, noise, vibration, thermal extremes, social disruption, crowding and restriction of movements [36]. Fluck [63] suggested that handling of chicks decreased forebrain aminobutyric acid (GABA) receptors and in vitro GABA release from brain tissues. Hence, it appears that reduced chickens' fear to humans is not the only possible explanation for the benefit of a positive human-animal interaction on farm animals.

When living organisms are exposed to thermal stresses, the synthesis of most proteins is retarded but a group of highly conserved proteins known as heat shock proteins (hsp) are rapidly synthesized [64]. In a heat shocked cell, hsp may bind to heat sensitive proteins and protect them from degradation, or may prevent damaged proteins from immediately precipitating and permanently affecting cell viability. It has been documented that stressors other than thermal stressors, for example feed restriction, confinement in crates, transportation and social isolation [65-68] may also elicit hsp 70 response in poultry. The induction of hsp is often associated with increased tolerance to environmental stressors and disease resistance [65,69]. Al-Aqil et al. [35] subjected broiler chickens to either pleasant or unpleasant negative human handling from 1 to $28 \mathrm{~d}$ of age. Following $3 \mathrm{~h}$ of road transportation, the chickens had lower heterophil / lymphocyte ratios, shorter TI duration and greater hsp 70 expression than those that were ignored or handled unpleasantly. Thus, it can be concluded that pleasant human contact may alter ability to tolerate road transportation stress through enhanced hsp 70 expression.

\section{The impact of stockmanship on animal productivity and welfare}

The factors commonly emphasised to improve farm animals' productivity are genetics, housing, nutrition, and health. There is, however, less emphasis on the quality of stockmanship. The way a stockperson carry out his or her routine animal care tasks may contribute to the overall relationship that animals have with humans and determine the relationship is positive, negative or neutral. Review of research in commercial pig and dairy farms showed a significant sequential relationships between stockpeoples' attitudes and behaviour towards animals and the fear of humans and productivity [70,71]. However, there is limited work in the poultry industry. Cransberg et al [72] investigated the relationship between stockperson attitude and behaviour, bird behaviour and productivity in 24 commercial broiler chicken farms. Unlike findings in pigs and dairy cattle, the authors failed to find a relationship between stockpeoples' attitude and behaviour. Although sequential relationships between human behaviour, bird behaviour and production were noted by the authors the magnitude of these relationships were not as substantial as found in pig and dairy industries. The lack of physical contact between stockperson and chickens and the large number of chickens managed by the stockpeople explanations for the results [72]. On the contrary, close physical contact between stockpeople and animals is common in pig and dairy farms.

The attitude of a stockperson holds about animals will strongly influence their behaviour towards animals [4]. The attitude and consequent behaviour of stockpeople affect the animals' fear of human which eventually influence animals' productivity and well-being. Other than attitude and behaviour, technical skills, knowledge, job motivation, commitment and job satisfaction are prerequisites for high job performance. Hence, proper selection and formal training of stockpeople are critical. Today, many countries, including Malaysia, are facing labour shortage in the agriculture sector. This may limit the capacity to select high potential stockpersons. Another possible limiting factor is the inadequate educational background of the stockpeople which may restrict their ability to be trained formally [4]. Thus, the content of the training programme has to be easily comprehensible by the target group. It is also critical that the animal industry recognizes and appreciates the stockpeoples' role in determining animal performance and welfare. Better financial rewards and clear career pathway for stockpeople would contribute to better motivation and job performance.

\section{Conclusion}

The preceding discussion clearly highlights the opportunity to improve productivity and welfare of farm animals through positive human-animal interactions. Most of the previous findings on human-animal interaction were based on laboratory studies. More on-farm studies, particularly in poultry, are required before appropriate operational strategies can be formulated for overall ease and feasibility of implementation in commercial settings. Factors such as genetic background, housing system, prior experience and individual variation may determine how an animal respond to human contact. The precise physiological mechanisms underpinning the effect of human-animal interactions on productivity and welfare of farm animals are unclear, although changes in ability to express heat shock proteins may be considered a possible route of action. The quality of stockmanship may markedly influence the productivity and welfare of farm animals. In intensive animal productions systems the tasks of managing and monitoring intensively-raised animals have been increasingly replaced by the use of modern technologies such as automation and surveillance cameras. Such technologies are labour-saving but opportunities for 
animals to interact with humans will be limited and thus, may exacerbate their natural fear of humans. A more regular visual contact with animals is necessary to dampen underlying fearfulness and physiological stress in farm animal. Hence, the attitude and behaviour of the stockpeople towards farm animals have to be emphasised.

\section{Competing interests}

The author declares that he has no competing interests.

Received: 3 May 2013 Accepted: 4 July 2013

Published: 15 July 2013

\section{References}

1. Siegel PB: Behavior-genetic analyses and poultry husbandry. Poult Sci 1993, 72:1-6.

2. Suarez SD, Gallup GG Jr: Open-field behaviour in chickens: the experimenter is a predator. J Comp Physiol Psycho 1982, 96:432-439.

3. Jones RB: Fear and distress. In Animal Welfare. Edited by Appleby MC, Hughes BO. Wallingford: CAB International; 1997:75-88.

4. Hemsworth PH, Coleman GJ: Human-Livestock Interactions: The Stockperson and the Productivity and Welfare of Intensively Farmed Animals. Wallingford: CAB International; 1998.

5. Hemsworth PH, Gonyou HW: Human contact. In Animal Welfare. Edited by Appleby MC, Hughes BO. Wallingford: CAB International; 1997:205-218.

6. Hemsworth $\mathrm{PH}$ : Human-animal interactions in livestock production. Appl Anim Behav Sci 2003, 85:185-198.

7. Waiblinger S, Boivin X, Pedersen V, Tosi MV, Janczak AM, Visser EK, Jones RB: Assessing the human-animal relationship in farmed species; A critical review. Appl Anim Behav Sci 2006, 101:185-242.

8. Jones RB: Fear and adaptability in poultry: insights, implications and imperatives. Wld's Poult Sci J 1996, 52:131-174.

9. Hemsworth $\mathrm{PH}$, Barnett JL: Human-Animal Interactions and Animal Stress. In The Biology of Animal Stress. Edited by Moberg GP, Mench JA. Wallingford: CAB International; 2000:309-315.

10. Estep $D Q$, Hetts $S$ : Interactions, relationships and bonds: the conceptual basis for scientist-animal relations. In The Inevitable Bond-Examining Scientist-Animal Interactions. Edited by Davis H, Balfour AD. Cambridge: CAB International; 1992:6-26.

11. Hemsworth PH, Coleman GJ, Cox M, Barnett JL: Stimulus generalization: the inability of pigs to discriminate between humans on the basis of their previous handling experience. Appl Anim Behav Sci 1994, 40:129-142.

12. Jones RB: Ontogeny of the response to humans in handled and nonhandled female domestic chicks. Appl Anim Behav Sci 1995, 42:261-269.

13. Tanida $H$, Nagano $Y$ : The ability of miniature pigs to discriminate stimuli between a stranger and their familiar handler. Appl Anim Behav Sci 1998 56:149-159.

14. Koba Y, Tanida H: How to miniature pigs discriminate between people? The effect of exchanging cues between a non-handler and their familiar handler on discrimination. J Anim Sci 1997 2001, 61:239-252.

15. Davies $\mathrm{H}$, Taylor A: Discrimination between individual humans by domestic fowl. Br Poult Sci 2001, 42:267-279.

16. Boivin $X$, Desprès Nowak $R$, Nowak $R$, Tournadre $H$, Le NP: Discrimination between shepherds by lambs reared under artificial conditions. J Anim Sci 1997, 75:2982-2898.

17. Rybarczyk P, Koba Y, Rusehn J, Tanida De Passille H: Recognition of people by dairy calves using colour of clothing. Appl Anim Behav Sci 2000 74:175-159.

18. Zulkifli I: Stress and disease development. In Diseases of Poultry in Southeast Asia. Edited by Zamri-Saad M. Serdang: UPM Press; 2006:1-8.

19. Moberg GP: Biological response to stress: Implications for animal welfare. In Biology of Animal Stress: Basic Principles and Implications for Animal Welfare. Edited by Moberg GP, Mench JA. Wallingford: CAB International; 2000:1-21.

20. Moberg GP: Biological response to stress: Key to assessment of animal well-being? In Animal Stress. Edited by Moberg GP. Bethesda, Maryland: American Physiological Society; 1985:27-49.
21. Jones RB: The assessment of fear in the domestic fowl. In Cognitive Aspects of Social Behaviour in the Domestic Fowl. Edited by Zayan R. Duncan: IJH: Amsterdam: Elsevier; 1987:40-81.

22. Craig JV, Adams AW: Behaviour and well-being of hens (Gallus domesticus) in alternative housing environments. Wld's Poult Sci J 1984, 40:221-240.

23. Gray JA: The Psychology of Fear and Stress. Cambridge, England: Cambridge University Press; 1987.

24. Dantzer $R$, Mormède $P$ : Stress in domestic animals: $A$ psychoneuroendocrine approach. In Animal Stress. Edited by Moberg GP. Bethesda, Maryland: American Physiological Society; 1985:81-96.

25. Zulkifli I, Dunnington EA, Gross WB, Larsen AS, Martin A, Siegel PB: Responses of dwarf and normal chickens to feed restriction, Eimeria tenella infection and sheep red blood cell antigen. Poult Sci, 72(193):1630-1640.

26. Zulkifli I, Siti Nor Azah A: Fear and stress reactions, and the performance of commercial broiler chickens subjected to regular pleasant and unpleasant contacts with human beings. Appl Anim Behav Sci 2004, 88:77-87.

27. Jones RB: The tonic immobility reaction of the domestic fowl. WIds' Poult Sci J 1986, 42:82-96.

28. Knowles TG, Broom DM: The handling and transport of broilers and spent hens. Appl Anim Behav Sci 1990, 28:75-91.

29. Zulkifli I, Che Norma MT, Chong CH, Loh TC: Heterophil/lymphocyte and tonic immobility reactions to pre-slaughter handling in broiler chickens treated with ascorbic acid. Poult Sci 2000, 79:402-406.

30. Zulkifli I, Che Norma MT, Chong CH, Loh TC: The effects of crating and road transportation on stress and fear responses of broiler chickens treated with ascorbic acid. Arch fur Geflugelk 2001, 65:33-37.

31. Hemsworth PH, Barnett $J$, Hansen C: The influence of handling by humans on the behaviour, growth and corticosteroids in the juvenile female pig. Hormones Behav 1981, 15:396-403.

32. Breuer $\mathrm{K}$, Hemsworth $\mathrm{PH}$, Coleman GJ: The effect of positive or negative handling on the behavioural and physiological responses of nonlactating heifers. Appl Anim Behav Sci 2003, 84:3-22.

33. Lyons DM, Price EO, Moberg GP: Individual differences in temperament of domestic dairy goats: Constancy and change. Anim Behav 1988, 36:1323-1333.

34. Zulkifli I, Gilbert J, Liew PK, Ginsos J: The effects of regular visual contact on tonic immobility, heterophil/lymphocyte ratio, antibody and growth responses in broiler chickens. Appl Anim Behav Sci 2002, 79:103-112.

35. Al-Aqil A, Zulkifli I, Hair Bejo M, Sazili AQ, Rajion MA, Somchit MN: Changes in heat shock protein 70 , blood parameters and fear-related behavior in broiler chickens as affected by pleasant and unpleasant human contact. Poult Sci 2013, 93:33-40.

36. Nicol CJ, Scott GB: Pre-slaughter handling and transport of broiler chickens. Appl Anim Behav Sci 1990, 58:57-73.

37. Lyons DM: Individual differences in temperament of dairy goats and the inhibition of milk injection. Appl Anim Behav Sci 1989, 22:269-282.

38. Jones RB: Reduction of domestic chick's fear of humans by regular handling and related treatments. Anim Behav 1993, 46:991-998.

39. Barnett JL, Hemsworth PH, Hennesy DP, McCallum TH, Newman EA: The effects of modifying the amount of human contact on behavioural, physiological and production responses of laying hens. App/ Anim Behav Sci 1994, 41:87-100.

40. Levine S: Stress and behavior. Scientific Am 1967, 224:26-31.

41. Gross WB: Chicken-environment interactions. In Ethics and Animals. Edited by Miller HB, Williams WH: C. New Jersey: Human Press; 1983:329-337.

42. Hemsworth PH, Barnett PH, Hansen C: The influence of handling by humans on the behavior, reproduction and corticosteroids of male and female pigs. Appl Anim Behav Sci 1986, 15:303-314.

43. Jones RB, Waddington D: Attenuation of the domestic chick's fear of human beings via regular handling: in search of a sensitive period. Appl Anim Behav Sci 1993, 36:1021-1033.

44. Gross WB, Siegel PB: Socialization as a factor in resistance to disease, feed efficiency, and response to antigen in chickens. Am J Vet Res 1982 43:2010-2012.

45. Jones RB, Hughes BO: Effects of regular handling on growth in male and female chicks of broiler and layer strains. Br Poult Sci 1981, 22:461-465

46. Collins JW, Siegel PB: Human handling, flock size and response to an $E$. coli challenge in young chickens. Appl Anim Behav Sci 1987, 19:183-188. 
47. Reichmann KG, Barram KM, Brock IJ, Standfast NF: Effects of regular handling and blood sampling by wing vein puncture on the performance of broilers and pullets. Br Poult Sci 1978, 19:97-99.

48. Freeman BM, Manning ACC: Stressor effects of handling on the immature fowl. Res Vet Sci 1979, 26:223-226.

49. Paterson AM, Pearce GP: Boar-induced puberty in gilts handled pleasantly or unpleasantly during rearing. Appl Anim Behav Sci 1989, 22:225-233.

50. Pearce GP, Paterson AM, Pearce AN: The influence of pleasant and unpleasant handling and provision of toys on the growth and behavior of male pigs. Appl Anim Behav Sci 1989, 23:27-37.

51. Rushen J, Munksgaard L, Marnet PG, Passillé D: Human contact and the effects of acute stress on cows at milking. Appl Anim Behav Sci 2001, 73:1-14.

52. Ader R, Cohen N: Psychoneuroimmunology: Conditioning and Stress. Ann. Rev Psychol 1993, 44:53-85.

53. Meaney MJ, Bhatnagar S, Diorio J, Larocque S, Francis D, O'Donnell O, Shanks N, Sharma S, Smythe J, Viau V: Molecular basis for the development of individual differences in the hypothalamic-pituitary-adrenal stress response. Cell Mol Neurobiol 1993, 13:321-347.

54. Blecha F: Immunomodulation: a means of disease prevention in stressed livestock. J Anim Sci 1988, 66:2084-2090.

55. Griffin JF: Stress and immunity: a unifying concept. Vet Immunol Immunopathol 1989, 20:263-312.

56. Zulkifli I, Siegel PB: Is there a positive side to stress? WId's Poult Sci J 1995, 51:63-76.

57. Siegel PB, Gross WB: General principles of stress and well-being. In Livestock Handling and Transport. Edited by Grandin T. Wallingford: CAB International; 2000:27-42.

58. Madden KS, Livnat S: Catecholamine action and immunologic reactivity. In Psychoneuroimmunology II. Edited by Ader R, Felten DL, Cohen N. San Diego: Academic Press; 1991:283-310.

59. Gross WB, Siegel PB: Influence of sequences of environmental factors on the response of chickens to fasting and to Staphylococcus aureus infection. Am J Vet Res 1982, 43:137-139.

60. Gross WB, Siegel PB: Socialization, the sequencing of environmental factors, and their effects on weight gain and disease resistance of chickens. Poult Sci 1983, 62:592-598.

61. Jones RB, Faure JM: The effects of regular handling on fear in the domestic chick. Behav Proc 1981, 6:135-143.

62. Jones RB, Waddington D: Modification of fear in domestic chicks, Gallus gallus domesticus via regular handling and early environmental enrichment. Anim Behav 1992, 43:1021-1033.

63. Fluck E, Hogg S, Jones RB, Bourne R, File SE: Changes in tonic immobility an dthe GABA: benzodiazepine system in response to handling in the chick. Pharmacol Bio-chem Behav 1997, 58:269-274.

64. Etches RJ, John TM, Verrinder Gibbins AM: Behavioural, physiological, neuroendocrine and molecular responses to heat stress. In Poultry Production in Hot Climates. Edited by Daghir NJ. CAB International; 1995:31-66.

65. Zulkifli I, Che Norma MT, Israf DA, Omar AR: The effects of early-age food restriction on heat shock protein 70 response in heat-stressed female broiler chickens. Br Poult SC 2002, 43:141-145.

66. Zulkifli I, Al-Aqil A, Omar AR, Sazili AQ, Rajion MA: Crating and heat stress influences blood parameters and heat shock protein 70 expression in broiler chickens showing short or long tonic immobility reactions. Poult Sci 2009, 88:471-476.

67. Al-Aqil A, Zulkifli l: Changes in heat shock protein 70 expression and blood parameters in transported broiler chickens as affected by housing and early age feed restriction. Poult Sci 2009, 88:1358-1364.

68. Soleimani AF, Zulkifli I, Omar AR, Raha AR: Neonatal feed restriction modulates circulating levels of corticosterone, and expression of glucorticoid receptor and heat shock protein 70 in aged Japanese quail exposed to acute heat stress. Poult Sci 2011, 90:1427-1434.

69. Liew PK, Zulkifli I, Hair-Bejo M, Omar AR, Israf DA: Effects of early age feed restriction and thermal conditioning on heat shock protein 70 expression, resistance to infectious bursal disease and growth in male broiler chickens subjected to chronic heat stress. Poult Sci 2003, 82:1879-1885.

70. Hemsworth PH, Barnett JL, Hansen Coleman GL: A study of the relationships between the attitudinal and behavioural profiles of stockpersons and the level of fear of humans and reproductive performance of commercial pigs. Appl Anim Behav Sci 1989, 23:301-314.
71. Coleman GJ, Hemsworth PH, Hay M: Predicting stockperson behaviour towards pigs from attitudinal and job-related variables and empathy. Appl Anim Behav Sci 1998, 58:63-76.

72. Cransberg PH, Hemsworth PH, Coleman GL: Human factors affecting the behaviour and productivity of commercial broiler chickens. Br Poult Sci 2000 41:272-279.

doi:10.1186/2049-1891-4-25

Cite this article as: Zulkifli: Review of human-animal interactions and their impact on animal productivity and welfare. Journal of Animal Science and Biotechnology 2013 4:25.

\section{Submit your next manuscript to BioMed Central and take full advantage of:}

- Convenient online submission

- Thorough peer review

- No space constraints or color figure charges

- Immediate publication on acceptance

- Inclusion in PubMed, CAS, Scopus and Google Scholar

- Research which is freely available for redistribution 